\title{
Research on Individualized Instruction of EGAP in General Engineering Colleges
}

\author{
Xixiang Ke \\ Wuhan Textile University, Wuhan, China 430070 \\ 1753270552@qq.com
}

Keywords: Individualized; EGAP; General engineering Colleges; Teaching mode

\begin{abstract}
The reform of academic English teaching in universities is in full swing. Some famous universities at home and abroad have implemented EGAP teaching, achieving remarkable results, while the effect in the general engineering colleges is undesirable merely by copying their successful experience. This paper via questionnaires and interviews attempts to find out the factors that block the reform in the general engineering colleges and explore EGAP teaching mode suitable for general engineering colleges. It is found that EGAP teaching is supposed to be need-oriented and conform to real situation of general engineering colleges. The general engineering colleges are supposed to combine their own learning situation, school situation and students' level with the successful experiences of famous universities to explore the teaching mode and methods with their own characteristics and apply them into practice.
\end{abstract}

\section{Introduction}

According to College English Teaching guidelines, the objective of College English Teaching should be diversified and individualized, and therefore teaching English for academic purposes, for general purposes pr for professional purposes depends on universities' objective so as to meet the various needs of students to a full extent.

That fact is that our country is in the transitional period of the society and economy, whether in a comprehensive university or the university with characteristics, the number of students after graduation who are not engaged in their professional work is more than that of students who take their professional work. In other words, in the era of new knowledge economy, knowledge is eliminated and changed very quickly. It is much more important to master the process and skills of acquiring knowledge than to acquire knowledge. For most students, interdisciplinary academic English skills and literacy training may be more than vital, for it is a source of innovation and of talent in twenty-first century.

The academic skills and scientific literacy listed above are indispensable to today's College graduates. Whether they continue research in the future workplace, whether they are engaged in technology development, work in the government sector, or in the company's sales department, the academic ability is the basic quality of all walks of life, information literacy is a must for them even though they may not use English someday. As Krzanowski [1] pointed out academic skills are ones that can be employed anywhere, which can help them cope with any new situation, thus EGAP is becoming known and a dominant in English education.

Throughout the years of the development of English education, the examination-oriented teaching purpose, dogmatic teaching methods and monotonous teaching content have become stumbling blocks to the development of English education. Facing this unsatisfactory situation, based on the background of the educational reform, the English education reform in our country is imminent.

\section{Relevant research}

English education reformers in China put forward a kind of new teaching mode of academic English education, which will liberate English learning from fixed English class and will expand English communication academically, English being not the mere teaching content, but being 
combined with teaching of other subjects. English being immersed in other subject learning makes English gradually an indispensable part of daily life for students [2]. Practice is the only way to improve their English ability, which academic English education maximizes [3]. This mode has been favored and implemented at home and abroad, remarkable results achieved.

However, this model has encountered many difficulties in general engineering colleges. Academic English courses are difficult to set up for the lack of qualified teachers and students' English proficiency. The purpose of this study is to explore the ways concerning a transition from English for General Purposes into English for Specific Purposes. English for General Academic Purposes is one part of English for Specific Purposes [4]. English for General Academic Purposes is what is needed to act as a bridge between EGP and the whole English courses.

EGAP is designed to cultivate students' academic vision, academic sensitivity and academic research ability [5], such as the ability to consult literature, write reports and papers, listen to lectures and so on. The teaching content of EGAP involves general discipline knowledge. Compared with professional English, the relatively broad materials enable students to learn something in different fields. The purpose of teaching is to train students' academic skills [6]. Thus it is not very demanding for teachers to teach EGAP after training and preparing lectures.

The purpose of this research is to solve three common problems existing in the English teaching of general engineering universities. College English teaching pays more attention to the input of language knowledge, ignoring the cultivation of pragmatic and practical competence, which can't meet the social needs. The content of College English teaching is mainly based on general English, ignoring the infiltration of other disciplines [7], and thus can't satisfy the needs of students' professional development. College English curriculum has a strong rigidity, which can meet the common requirements of students, but can't meet the individual needs of students, eventually failing to meet the requirement of country.

\section{Research method}

Questionnaires investigation and interviews are conducted. The questionnaire deals with students' individual needs and students' needs in the learning of EGAP. The questions asked in the interview are as follows: What are your opinions and suggestions of EGAP concerning the course content, teaching design, teaching materials, and teaching methods etc. The number of questionnaires issued is 500, and 494 questionnaires are valid. The number of people interviewed reaches 100, involving 20 majors.

\section{Results and discussion}

The results of questionnaires and interviews show that the needs of students are diverse, involving the following aspects. The first is the demand of proper textbooks. The existing textbooks in market are compiled by Cai Jigang whose textbooks deal with management, engineering, social sciences. These textbooks are employed in famous universities, yielding good effect. However, the difficulty index is not fit for students in general engineering colleges who have difficulty in learning thus losing confidence in the study[8]. Therefore, it is urgent to compile a set of teaching materials suitable for general engineering colleges. Second, there is great demand for qualified teachers. Students need teachers who understand the relevant discipline knowledge, and this poses challenges to teachers. Third, fewer teaching periods are available for students to learn this course-EGAP. Fourth, students need a student-centered teaching mode. Group cooperation, online and offline blended teaching and learning are indispensable. This indicates students' strong desire to participate in the classroom. Fifth, as for teaching content, students hope that the knowledge teachers convey in class is relevant to textbooks, such as background information, current hot spots combined with real life. Sixth, a new teaching design is necessary and the new curriculum should have new teaching design. The purpose of EGAP teaching is different from that of general English, so the teaching design should also serve the purpose of EGAP teaching. Seventh, traditional teaching method-grammar translation should not be the mere way to teach because of the increase of 
difficulty. Students reflect that this method is time consuming and ineffective, which can't arouse interest. It is better for teachers to draw emphasis on teaching content and enable students to participate in the teaching and learning. Eighth, emotional need is a factor that can't be ignored. Students need emotional attention. Teachers' timely communication and attention are necessary for students. Ninth, the reform of teaching system is around the corner. Finally, existing assessment and testing system is out of date, which can not measure academic ability of students. The EGAP test measures the test takers' academic skills and literacy as well as language abilities. It helps students across disciplines to use English in their academic studies and their future work. Therefore it's necessary and vital to improve testing system.

Corresponding solutions are as follows.

Compile academic English textbooks for students, which can be divided into four categories: management, science and engineering, art and humanities. During the process, consult the experts and professors on discipline knowledge in related fields. The textbook are supposed to be needoriented, whose compiling is based on real cases and real obstacles of students.

Holding large-scale teacher training on weekends or in summer holidays is an urgent task. The training involves all aspects of teaching. Workshops and seminars can be held for teachers to learn from each other and from famous experts and professors in EGAP teaching. Teaching group can be organized to cultivate teachers specialized in EGAP teaching. The members of EGAP teaching group cooperate with teachers from such departments as management, science, engineering, humanity and art in preparing lectures, mutual teaching and compiling textbooks. Communicate with the educational administration department and thus increase the teaching periods appropriately. Financial support from administration is vital for the transition from EGP to EGAP.

The combination mode of online and offline, and the combination of tradition and modernity is adopted. Textbooks as well as extracurricular handouts are used in lecturing. The handout contains the latest materials related to the topics of texts and can be obtained from newspapers, magazines, the Internet, and blogs. For example, academic papers exploited in class can be from real academic journals.

Teaching system is to be changed. EGP is combined with EGAP during the four semesters. English Course for General Purposes is set up during the first two semesters for students to lay foundation. The next two semesters are for English courses for general academic purposes [9].

Testing system is adopted in which formative assessment is blended with summative assessment [10]. Formative assessment is conducted in the form of research project measuring listening and speaking ability, while summative assessment in the form of final written test, testing reading and writing ability.

As a part of ESP, the research of EGAP corpus in various aspects is needed. Some professional vocabulary can be collected in the establishment of corpus, and professional vocabulary is to be included in the teaching syllabus [11]. This lays a foundation for ESP testing. Besides, professional setting can be researched as well to serve ESP teaching. Student forum can be organized for student and teachers to communicate each other. Micro-lecture can be filmed [12]. All of these serve as ESP teaching materials for sharing.

\section{Conclusion}

EGAP teaching should be need-oriented to satisfy the needs of country and the individual needs of students in various aspects. The general engineering colleges are supposed to combine their own learning situation, school situation and students' level with the successful experiences of famous universities to explore the teaching mode and methods with their own characteristics and apply them into practice. Then approaches to the integration of the national requirements with the undergraduates' foreign language capacity in the perspective of individualized instruction and individual needs are possible. Only in this way can the engineering talents adapting to the society be cultivated. 


\section{Acknowledgement}

This work was financially supported by Hubei Provincial Department of Education and Wuhan Textile University (201608014).

\section{References}

[1] Krzanoswki, M. EAP draws on mixed methods as holistic view incorporated [J].English Language Journal Opening Doors across the World, 1999, (3).

[2] Blossom, W. Content-based unit learning in English for academic purposes courses in teachers' colleges [J]. Adolescent \& Adult Literacy. 2001 (44): 372-381.

[3] Coyle, D.,P. Hood\& D. Marsh. CLIL: Content and Language Integrated Learning [M]. Cambridge: CUP. 2010.

[4] Song, B. Content-based ESL instruction: Long-term effects and outcomes [J]. English for Specific Purposes 2006 (25): 420-437.

[5] Cai Jigang. ESP in China: Yesterday, Today and Tomorrow [J]. Journal of University of Shanghai for Science and Technology2016 (2):106-113.(In Chinese)

[6] Cai Jigang.. A study of CET of four Japanese universities and the objectives of China CET [J]. Foreign Language Learning Theory and Practice 2012 (3): 1 -7. (In Chinese)

[7] Paran. A. CLIL: Content and Language Integrated Learning [J]. ELTJ 2013(1):137-141.

[8] Cai Jigang. Testing English for General or Specific Purposes-a Study on the Re-orientation of College English Test [J].Computer-Assisted Foreign Language Education2012 (146): 27-32. (In Chinese)

[9] Cai Jigang. Development and Prospects of ESP [J]. Journal of Xi'an International Studies University2015 (1):68-72. (In Chinese)

[10] Cai Jigang. A study of English Testing for general Academic Purposes [J]. Shandong Foreign Language Teaching 2015 (4 ):40-46. (In Chinese)

[11] Cai Jigang. The Implication of the Shift from EGP to ESP in National Cheng Kung University, Taiwan [J]. Foreign Language Learning Theory and Practice 2013 (3): 94 -99. (In Chinese)

[12] Cai Jigang. Zero distance approach to the integration of the national requirements with the undergraduates' foreign language capacity in the perspective of individualized instruction and individual needs [J]. Journal of Yunnan Normal University 2016 (3):33-39. (In Chinese) 